Comunicação

\title{
Estratégias de seleção para germinação de sementes de cenoura em condições de temperaturas elevadas
}

\author{
Giovani Olegário da Silva ${ }^{1 *}$, Jairo Vidal Vieiral, Warley Marcos Nascimento ${ }^{1}$, Leonardo Silva Boiteux ${ }^{2}$
}

\section{RESUMO}

O objetivo deste trabalho foi definir estratégias mais adequadas de seleção e verificar a efetividade dessas estratégias para aumentar a taxa de germinação de sementes de cenoura em duas temperaturas $\left(20\right.$ e $\left.35^{\circ} \mathrm{C}\right)$. A primeira contagem (vigor) e a taxa de germinação de sementes foram utilizadas como critérios de avaliação. Foram estudadas 27 populações de cenoura (derivadas do cultivar Brasília) e três cultivares (testemunhas). Foi utilizado um delineamento em blocos casualizados com três repetições de 50 sementes de cada material genético. Foram estimados os padrões de correlação entre os caracteres, e as médias entre os tratamentos foram comparadas. Vigor e taxa de germinação apresentaram-se significativos em diferenciar as populações avaliadas. Não foi observada correlação significativa entre as duas temperaturas para os dois caracteres. Dessa forma, a seleção deve ser efetuada em conjunto nas duas temperaturas, para evitar a potencial perda da adaptação em uma delas. A primeira contagem e a taxa de germinação apresentam correlações elevadas dentro de cada temperatura, indicando que se pode optar pela avaliação de apenas um caractere.

Palavras-chave: Daucus carota L., termoinibição, estabelecimento de plântulas.

\section{ABSTRACT}

\section{Selection strategies for germination of carrot seeds at high temperatures}

The objective of this work was to determine the best selection strategy to improve seed germination rate and assess their effectiveness at two temperatures $\left(20^{\circ} \mathrm{C}\right.$ and $35^{\circ} \mathrm{C}$ ). First count (vigor) and germination rate at $20^{\circ} \mathrm{C}$ and $35^{\circ} \mathrm{C}$ were used as evaluation criteria. Seeds of 27 carrot breeding populations derived from cultivar Brasília and three commercial standard cultivars were used in a randomized block design with three replications of 50 seeds for each accession. The correlation pattern among traits was estimated and treatment means were compared. First count (vigor) and germination were significant among populations. No correlation was observed between first count and germination rate at the two temperatures. This result suggests that selection for increasing seed germination should be carried out at both temperatures in order to avoid potential loss of adaptation to one of them. First count and seed germination rate had high correlations at each temperature, indicating that a single character could be used in the evaluation.

Key words: Daucus carota L., term-inhibition, plantlet establishment.

\footnotetext{
Recebido para publicação em agosto de 2009 e aprovado em janeiro de 2011

${ }^{1}$ Engenheiros-Agrônomos, Doutores. Empresa Brasileira de Pesquisa Agropecuária, Centro nacional de Pesquisa de Hortaliças, CP 218, 70359-970, Brasilia, DF, Brasil. olegario@cnph.embrapa.br, jairo@cnph.embrapa.br,wmn@cnph.embrapa.br, *Autor correspondente.

${ }^{2}$ Engenheiro-Agrônomo, Ph. Doctor. Empresa Brasileira de Pesquisa Agropecuária, Centro nacional de Pesquisa de Hortaliças, CP 218, 70359-970, Brasilia, DF, Brasil.
} 


\section{INTRODUÇÃO}

Estresses abióticos podem resultar no atraso ou mesmo na inibição completa da germinação de sementes de hortaliças (Hegarty, 1977). A germinação das sementes de cenoura (Daucus carota L.) ocorre em temperaturas de 8 a $35^{\circ} \mathrm{C}$, e a velocidade e uniformidade de germinação variam com a temperatura dentro desses limites. A faixa ideal para a germinação rápida e uniforme é de 20 a $30^{\circ} \mathrm{C}$, ocorrendo a emergência entre sete e 10 dias após a semeadura (Vieira et al., 1999). Altas temperaturas por ocasião do plantio podem atrasar ou inibir a germinação das sementes de cenoura (Pereira \& Nascimento, 2002). Falhas na obtenção de estandes uniformes têm sido um dos grandes problemas nessa cultura, principalmente nas épocas mais quentes do ano.

As condições de estresse induzido por elevadas temperaturas de solo estão presentes em algumas regiões produtoras de cenoura e regiões com potencial para produção dessa hortaliça no Brasil. Dessa forma, o desenvolvimento de cultivares com melhor taxa de germinação nestas condições ambientais poderia permitir a expansão da fronteira geográfica desta hortaliça no Brasil. De fato, o desenvolvimento de cultivares de cenoura com tolerância ao calor e resistência às principais doenças da cultura propiciou, em anos recentes, significativo aumento da área de cultivo em regiões de clima quente, principalmente no Nordeste e CentroOeste do Brasil.

Dentre os cultivares de cenoura desenvolvidos para o cultivo durante o verão, destacam-se aqueles do grupo varietal Brasília, incluindo Alvorada, Brasília e Esplanada. Estes cultivares apresentam desempenho superior em relação aos outros comercializados no País quanto à produtividade, resistência ao complexo queima-das-folhas e adaptação às condições de cultivo durante o verão (Vieira et al., 2005). Entretanto, quanto à capacidade de germinação em temperaturas elevadas (acima de $35^{\circ} \mathrm{C}$ ), o desempenho desses cultivares, similarmente aos demais em uso no Brasil, não se mostrou satisfatório (Pereira et al., 2007, Pereira \& Nascimento, 2002).

Esse desempenho inferior de germinação resulta na redução de estande e em menores níveis de produtividade que pode ser observado, por exemplo, no menor poder germinativo de sementes, especificamente do cultivar Brasília em algumas micro-regiões (por exemplo, Irecê-BA) nos meses mais quentes do ano (Pereira $e t$ al., 2007).

A produção de novos cultivares atendendo a esses interesses deve ser baseada em métodos eficientes que possibilitem a utilização de estratégias de seleção que reduzam custos e permitam adequada avaliação e identificação de genótipos superiores. Nesse sentido, o programa de melhoramento da Embrapa Hortaliças vem dirigindo esforços para pesquisas nessa área, visando adequar métodos eficientes para serem utilizados como rotina e selecionando algumas populações capazes de germinar em taxas elevadas tanto para temperaturas mais amenas $\left(20^{\circ} \mathrm{C}\right)$ quanto para temperaturas elevadas (35 $\left.{ }^{\circ} \mathrm{C}\right)$.

O objetivo deste trabalho foi definir melhores estratégias de seleção e verificar a sua efetividade para as temperaturas de 20 e $35^{\circ} \mathrm{C}$, utilizando-se sementes de populações de cenoura em fase de melhoramento.

\section{MATERIAL E MÉTODOS}

Os experimentos foram conduzidos no Distrito Federal, no ano de 2007. Foram avaliadas 27 populações de cenoura originadas do cultivar Brasília e três cultivares como testemunhas: Brasília, Alvorada e Esplanada, utilizando-se um delineamento em blocos casualizados com três repetições e 50 sementes por parcela de cada população. As sementes foram colocadas em caixas gerbox, sobre duas folhas de papel mata-borrão umedecidas com $15 \mathrm{~mL}$ de solução fungicida (Iprodione + Thiram 3:1/4 g por $1.000 \mathrm{~mL}$ de água destilada) por caixa. Em seguida, as sementes foram colocadas para germinar em câmara do tipo NKSystem, sob luz artificial, regulada para temperatura do ar de 20 e a $35^{\circ} \mathrm{C}$. Independentemente da temperatura de realização do ensaio, as famílias foram avaliadas aos sete dias após a semeadura (primeira contagem), o que corresponde a uma avaliação do vigor de sementes de cenoura (Bittencourt, 1991), e aos 14 dias (contagem final). Os resultados obtidos foram expressos em porcentagem média de sementes germinadas (protrusão da raiz primária).

Foram verificadas as pressuposições de homogeneidade de variância (Bartllet's test for heterogeneity of error variances) e de normalidade (Lilliefors's test statistic). Os dados dos dois caracteres nas duas temperaturas foram transformados por arco seno da raiz quadrada da proporção, para atender à pressuposição de normalidade de distribuição. Efetuou-se uma análise de variância para cada temperatura e conjunta para as duas temperaturas. Foram também estimadas a correlação genotípica entre os caracteres e o agrupamento de médias dos tratamentos por Scott e Knott, utilizando-se o aplicativo computacional Genes (Cruz, 1997).

\section{RESULTADOS E DISCUSSÃO}

De acordo com as análises de variância para cada temperatura, todos os caracteres foram significativos 
Tabela 1. Resumo da análise de variância e estimativa dos valores da relação coeficiente de variação genética sobre coeficiente de variação ambiental (CVg/Cve) para os caracteres vigor e germinação de sementes de cenoura utilizando-se 27 populações de cenoura e três testemunhas comerciais avaliadas em condições de laboratório em temperatura de 20 e $35^{\circ} \mathrm{C}$

\begin{tabular}{|c|c|c|c|}
\hline \multirow{2}{*}{ Fonte de variação } & \multirow{2}{*}{ GL } & \multicolumn{2}{|c|}{ Quadrado Médio } \\
\hline & & Vigor & Germinação \\
\hline & & \multicolumn{2}{|c|}{ Temperatura $20^{\circ} \mathrm{C}$} \\
\hline Bloco & 2 & 0,001 & 0,001 \\
\hline Populações & 29 & $0,03 *$ & $0,03^{*}$ \\
\hline Resíduo & 58 & 0,01 & 0,01 \\
\hline $\mathrm{CVe}$ & - & 5,73 & 6,17 \\
\hline $\mathrm{CVg} / \mathrm{CVe}$ & - & 1,28 & 1,16 \\
\hline \multirow[t]{2}{*}{ Média não transformada } & - & 85,42 & 87,69 \\
\hline & & \multicolumn{2}{|c|}{ Temperatura $35^{\circ} \mathrm{C}$} \\
\hline Bloco & 2 & 0,10 & 0,32 \\
\hline Populações & 29 & $0,02 *$ & $0,04 *$ \\
\hline Resíduo & 58 & 0,01 & 0,02 \\
\hline $\mathrm{CVe}$ & - & 69,00 & 45,00 \\
\hline $\mathrm{CVg} / \mathrm{CVe}$ & - & 0,63 & 0,73 \\
\hline \multirow[t]{2}{*}{ Média não transformada } & - & 3,80 & 9,80 \\
\hline & & \multicolumn{2}{|c|}{ Conjunta } \\
\hline Populações & & 0,02 & 0,03 \\
\hline Temperaturas $(\mathrm{T})$ & & $48,84^{*}$ & $40,74 *$ \\
\hline Populações x T & & $0,03^{*}$ & $0,04 *$ \\
\hline Resíduo & & 0,01 & 0,01 \\
\hline
\end{tabular}

*Significativo a $1 \%$ de probabilidade de erro pelo teste $\mathrm{F}$

em diferenciar os genótipos avaliados. A análise de variância conjunta indicou a presença de interação significativa entre genótipos e temperaturas, dessa forma as inferências foram feitas para cada temperatura (Tabela 1).

Para $20^{\circ} \mathrm{C}$ os coeficientes de variação foram reduzidos, indicando boa precisão experimental, e os valores da relação entre o coeficiente de variação genético e o de variação ambiental foram de 1,28 e 1,16, indicando que existe a possibilidade de obter ganhos com a seleção. No entanto, a temperatura de $20^{\circ} \mathrm{C}$, recomendada para testes de germinação de cenoura (Brasil, 1992), é inferior às do solo comumente observadas no plantio de verão nas condições de clima da maioria das regiões brasileiras.

Para $35^{\circ} \mathrm{C}$ os coeficientes de variação foram elevados para ambos os caracteres, devido à grande variação nos resultados das diferentes repetições de cada material, indicando a necessidade de incorporar modificações no método visando minimizar este problema. Elevados valores do coeficiente de variação para essa temperatura também foram observados por Silva et al. (2010). Os valores da relação entre o coeficiente de variação genético e o ambiental foram abaixo de 1, indicando que o ambiente influenciou predominantemente na expressão dos caracteres nessas condições experimentais (Tabela 1).
Os valores médios de germinação e vigor também foram muito reduzidos na temperatura mais alta. Na primeira contagem as porcentagens médias reduziram-se de 85,42 para $3,80 \%$, enquanto a germinação final foi reduzida de 87,69 para $9,80 \%$ a 20 e $35^{\circ} \mathrm{C}$, respectivamente. Estes resultados indicam que maior atenção deve ser dada à seleção na temperatura de $35^{\circ} \mathrm{C}$, pois a $20^{\circ} \mathrm{C}$ as germinações de todas as populações são elevadas e atendem às normas brasileiras (Brasil, 1992). Da mesma forma, Pereira et al. (2007) verificaram que a $35^{\circ} \mathrm{C}$ poucas progênies de meio-irmãos derivadas de Brasília apresentaram germinação superior a 60\%. Pereira et al. (2007) observaram ainda que $27 \%$ das populações avaliadas não tiveram nenhuma semente germinada a $35^{\circ} \mathrm{C}$. Tendência semelhante foi verificada por Carneiro \& Guedes (1992), em que sementes do cultivar Brasília germinaram $91 \%$ a $25^{\circ} \mathrm{C}$ e apenas $47 \%$ a $35^{\circ} \mathrm{C}$. Silva et al. (2010) estimaram maiores ganhos esperados com a seleção de famílias a $35^{\circ} \mathrm{C}$ em comparação com $20^{\circ} \mathrm{C}$ para uma população do grupo Brasília.

Outra constatação importante foi a ausência de correlação significativa entre as duas temperaturas para os dois caracteres, sendo de 0,12 para a primeira contagem e 0,05 para a germinação (Tabela 2), o que indica a ausência de ligação gênica ou pleiotropia no controle dos caracteres e que a seleção para um caractere não influencia na expressão do outro. Dessa forma, deve-se reali- 
zar a seleção para germinação em temperaturas elevadas e também para temperaturas mais baixas, para evitar a potencial perda da adaptação para germinação em temperaturas mais amenas. Da mesma forma, Silva et al. (2010) verificaram pouca coincidência na escolha das melhores famílias de uma população de cenoura nas temperaturas de 20 e $35^{\circ} \mathrm{C}$.

Os resultados da correlação genética indicam também que a $20^{\circ} \mathrm{C}$ a primeira contagem e germinação apresentaram correlação de 0,98 , e para $35^{\circ} \mathrm{C}$ de 0,99 (Tabela 2). Dessa forma, pode-se optar pela avaliação apenas da germinação de sementes, com economia de mão de obra e menor tempo com as avaliações. Estimativas elevadas de correlação entre primeira contagem e germinação também foram obtidas por Silva et al. (2010), 0,82 a $20^{\circ} \mathrm{Ce} 0,95$ a $35^{\circ} \mathrm{C}$.

Pela comparação das médias (Tabela 3), verificou-se que a $20^{\circ} \mathrm{C}$ a população 0712475 esteve agrupada entre as de maior valor de primeira contagem e geminação, com 96,67 e $97,33 \%$, respectivamente. Essa população foi sele- cionada por três ciclos consecutivos para germinação na temperatura de $20^{\circ} \mathrm{C}$, sendo superior estatisticamente às testemunhas, indicando que o processo de seleção dessa população nessa temperatura foi eficiente em aumentar a germinação a $20^{\circ} \mathrm{C}$. A população 0712480 (que foi selecionada em ambas as temperaturas: 20 e $35^{\circ} \mathrm{C}$ ) também esteve entre as de maior germinação a $20^{\circ} \mathrm{C}$ e para os dois caracteres a $35^{\circ} \mathrm{C}$.

Tabela 2. Correlações genotípicas entre os caracteres vigor e germinação de sementes de cenoura utilizando-se 27 populações de cenoura e três testemunhas comerciais avaliadas em condições de laboratório sob temperatura de 20 e $35^{\circ} \mathrm{C}$

\begin{tabular}{lccc}
\hline & PC $20^{\circ} \mathrm{C}$ & GER 20 $^{\circ} \mathrm{C}$ & ${\text { PC } 35^{\circ} \mathrm{C}}^{\circ}$ \\
\hline GER $20^{\circ} \mathrm{C}$ & $0,98^{*}$ & & \\
PC $35^{\circ} \mathrm{C}$ & 0,12 & 0,17 & \\
GER $35^{\circ} \mathrm{C}$ & 0,05 & 0,05 & $0,99^{*}$ \\
\hline
\end{tabular}

*Significativo a $5 \%$ pelo teste T. PC: primeira contagem; e GER: germinação

Tabela 3. Comparações de médias por Scott Knott para os caracteres vigor e germinação de sementes de cenoura utilizando-se 27 populações de cenoura e três testemunhas comerciais avaliadas em condições de laboratório em temperatura de 20 e $35^{\circ} \mathrm{C}$

\begin{tabular}{|c|c|c|c|c|}
\hline \multirow[b]{2}{*}{ População } & \multicolumn{2}{|c|}{$20^{\circ} \mathrm{C}$} & \multicolumn{2}{|c|}{$35^{\circ} \mathrm{C}$} \\
\hline & $\mathbf{P C}^{1}$ & Ger $^{2}$ & PC & Ger \\
\hline 0712461 & $91,33 \mathrm{a}^{*}$ & $92,00 \mathrm{a}$ & $6,67 \mathrm{a}$ & $20,00 \mathrm{a}$ \\
\hline 0712462 & $83,33 \mathrm{~b}$ & $88,00 \mathrm{~b}$ & $6,67 \mathrm{~b}$ & $16,67 \mathrm{a}$ \\
\hline 0712463 & $84,00 \mathrm{~b}$ & $84,00 \mathrm{~b}$ & $2,00 \mathrm{~b}$ & $8,00 \mathrm{~b}$ \\
\hline 0712464 & $82,67 \mathrm{~b}$ & $87,33 \mathrm{~b}$ & $3,33 \mathrm{~b}$ & $7,33 \mathrm{~b}$ \\
\hline 0712465 & $76,67 \mathrm{~b}$ & $82,00 \mathrm{~b}$ & $0,00 \mathrm{~b}$ & $0,00 \mathrm{~b}$ \\
\hline 0712466 & 80,67 b & $82,67 \mathrm{~b}$ & $3,33 \mathrm{a}$ & $6,00 \mathrm{~b}$ \\
\hline 0712467 & $92,67 \mathrm{a}$ & 94,67 a & $4,67 \mathrm{a}$ & $10,00 \mathrm{a}$ \\
\hline 0712468 & $88,00 \mathrm{a}$ & $92,67 \mathrm{a}$ & $2,67 \mathrm{~b}$ & $8,00 \mathrm{~b}$ \\
\hline 0712469 & 86,67 a & $92,67 \mathrm{a}$ & $3,33 \mathrm{~b}$ & $4,00 \mathrm{~b}$ \\
\hline 0712470 & 86,67 a & $90,00 \mathrm{a}$ & $12,67 \mathrm{a}$ & $20,67 \mathrm{a}$ \\
\hline 0712471 & $78,67 \mathrm{~b}$ & $82,67 \mathrm{~b}$ & $0,67 \mathrm{~b}$ & $4,00 \mathrm{~b}$ \\
\hline 0712472 & $91,33 \mathrm{a}$ & $93,33 \mathrm{a}$ & $2,67 \mathrm{~b}$ & $7,33 \mathrm{~b}$ \\
\hline 0712473 & $86,00 \mathrm{~b}$ & 88,67 a & $1,33 \mathrm{~b}$ & $3,33 \mathrm{~b}$ \\
\hline 0712474 & $92,00 \mathrm{a}$ & $93,33 \mathrm{a}$ & $0,67 \mathrm{~b}$ & $10,00 \mathrm{~b}$ \\
\hline 0712475 & 96,67 a & $97,33 \mathrm{a}$ & $2,00 \mathrm{~b}$ & $4,67 \mathrm{~b}$ \\
\hline 0712476 & $82,00 \mathrm{~b}$ & $84,00 \mathrm{~b}$ & $6,67 \mathrm{a}$ & $14,67 \mathrm{a}$ \\
\hline 0712477 & $92,67 \mathrm{a}$ & $94,00 \mathrm{a}$ & $4,00 \mathrm{a}$ & $9,33 \mathrm{a}$ \\
\hline 0712478 & $80,00 \mathrm{~b}$ & $81,33 \mathrm{~b}$ & $2,00 \mathrm{~b}$ & $10,00 \mathrm{a}$ \\
\hline 0712479 & 90,67 a & $91,33 \mathrm{a}$ & $0,67 \mathrm{~b}$ & $4,67 \mathrm{~b}$ \\
\hline 0712480 & $90,67 \mathrm{a}$ & $91,33 \mathrm{a}$ & $14,00 \mathrm{a}$ & $24,67 \mathrm{a}$ \\
\hline 0712481 & 89,33 a & $92,67 \mathrm{a}$ & $4,67 \mathrm{a}$ & $12,67 \mathrm{a}$ \\
\hline 0712482 & $82,67 \mathrm{~b}$ & $83,33 \mathrm{~b}$ & $4,00 \mathrm{a}$ & $11,33 \mathrm{a}$ \\
\hline 0712483 & $95,33 \mathrm{a}$ & $95,33 \mathrm{a}$ & $0,00 \mathrm{~b}$ & $9,33 \mathrm{~b}$ \\
\hline 0712484 & $80,67 \mathrm{~b}$ & $81,33 \mathrm{~b}$ & $4,00 \mathrm{a}$ & $6,00 \mathrm{~b}$ \\
\hline 0712485 & $90,00 \mathrm{a}$ & $91,33 \mathrm{a}$ & $2,67 \mathrm{~b}$ & $4,00 \mathrm{~b}$ \\
\hline 0712488 & $78,00 \mathrm{~b}$ & $80,67 \mathrm{~b}$ & $0,67 \mathrm{~b}$ & $2,67 \mathrm{~b}$ \\
\hline 0712489 & $84,00 \mathrm{~b}$ & $87,33 \mathrm{~b}$ & $0,67 \mathrm{~b}$ & $2,00 \mathrm{~b}$ \\
\hline Alvorada & $83,33 \mathrm{~b}$ & $84,67 \mathrm{~b}$ & $6,67 \mathrm{a}$ & $20,00 \mathrm{a}$ \\
\hline Esplanada & $65,33 \mathrm{c}$ & $66,00 \mathrm{c}$ & $5,33 \mathrm{a}$ & $14,00 \mathrm{a}$ \\
\hline Brasília & 80,67 b & $84,67 \mathrm{~b}$ & $5,33 \mathrm{a}$ & $18,67 \mathrm{a}$ \\
\hline
\end{tabular}

* Médias seguidas de letras diferentes na coluna diferem estatisticamente por Scott Knott a 5\%. ${ }^{1}$ Primeira contagem (vigor); e ${ }^{2}$ germinação 


\section{CONCLUSÕES}

Não existe correlação para primeira contagem e germinação entre as temperaturas $20 \mathrm{e} 35^{\circ} \mathrm{C}$, desta forma, a seleção visando aumento de germinação deve ser efetuada para temperaturas mais amenas e também para mais elevadas.

Dentro de cada temperatura, primeira contagem e germinação apresentam correlações elevadas, indicando que se pode optar pela avaliação apenas para o caractere germinação de sementes.

\section{REFERENCIAS}

Bittencourt MLC (1991) Qualidade de sementes e avaliação das progênies de meio-irmãos de cenoura (Daucus carota L.) "Brasília". Dissertação Mestrado. Universidade Federal de Viçosa, Viçosa, 77p.

Brasil Ministério da Agricultura (1992) Regras para análise de sementes. LANARV/MA, Brasilia. 365p.

Carneiro JVP \& Guedes TA (1992) Influência da temperatura no desempenho germinativo de sementes de cenoura (Daucus carota L.), avaliada pela função de distribuição de Weibull. Revista Brasileira de Sementes, 14:207-213.

Cruz CD (1997) Programa Genes: aplicativo computacional em genética e estatística. UFV, Viçosa. 442p.

Hegarty TW (1977) Seed activation and seed germination under moisture stress. New Phytologist, 78: 349-359.

Pereira RS, Nascimento WM \& Vieira JV (2007) Germinação e vigor de sementes de cenoura sob condições de altas temperaturas. Horticultura Brasileira, 25:215-219.

Pereira RS \& Nascimento WM (2002) Utilização do condicionamento osmótico de sementes de cenoura visando à germinação em condições de temperaturas altas. In: $42^{\circ}$ Congresso Brasileiro de Olericultura e $11^{\circ}$ Congresso Latino-Americano de Horticultura, Uberlândia. Horticultura Brasileira. CD-ROM. 2002 .

Silva GO, Vieira JV \& Nascimento WM (2010) Estratégias de seleção para germinação de sementes de cenoura em alta temperatura. Revista Ceres, 57:60-65.

Vieira JV, Pessoa HBSV \& Makishima N (1999) A cultura da cenoura/Embrapa Hortaliças, Coleção plantar 43, Brasília. 77p.

Viera, JV, Silva JBC, Charchar JM, Resende FV, Fonseca MEN, Carvalho AM, Machado CMM (2005) Esplanada: cultivar de cenoura de verão para fins de processamento. Horticultura Brasileira, 23:851-852. 